\title{
SOME POSSIBLE REVISIONS TO THE SEISMIC PROVISIONS OF THE NEW ZEALAND CONCRETE DESIGN CODE FOR MOMENT RESISTING FRAMES
}

\author{
P. C. Cheung1, T. Paulay ${ }^{2}$ and R. Park ${ }^{3}$ \\ This paper was presented at the Pacific Conference on Earthquake Engineering, \\ Auckland November 1991.
}

\begin{abstract}
SUMMARY
Possible revisions to the seismic design provisions of the New Zealand concrete design code NZS 3101:1982 for ductile reinforced concrete moment resisting frames are discussed. Topics include shear reinforcement for beam-column joint cores, anchorage of longitudinal reinforcement passing through beam-column joint cores, and transverse reinforcement in columns for confinement in potential plastic hinge regions of columns. The recommendations are based on recent experimental and theoretical studies of the simulated seismic response of beam-column joints and columns in ductile reinforced concrete frames. Rational models for the evaluation of behaviour are presented.
\end{abstract}

\section{INTRODUCTION}

The current New Zealand concrete design code NZS 3101:1982 [8] was written mainly in the late 1970s. The code was based mainly on the 1977 building code of the American Concrete Institute [1] but with additional seismic provisions based on the results of research and experience in New Zealand and elsewhere available at that time. Many pioneering seismic design provisions were introduced in NZS 3101:1982. These were based on a rational capacity design procedure and recommendations were made for the detailing of reinforcement to ensure the most desirable behaviour of structures during severe earthquakes.

In the decade since NZS 3101:1982 was published further theoretical and experimental research has been conducted in New Zealand and the structural damage caused by several severe earthquakes overseas has been assessed. In particular, research into the seismic behaviour of reinforced concrete beamcolumn joints and columns has continued. An amendment to NZS 3101:1982 has been issued [9], mainly to take into account the new reinforcing steel grades manufactured in New Zealand.

This paper presents some further possible revisions to the seismic design provisions of NZS 3101 for ductile reinforced concrete moment resisting frames.

${ }^{1}$ Former PhD student, Dept. of Civil Engineering, University of Canterbury (Member)

${ }^{2}$ Emeritus Professor of Civil Engineering, University of Canterbury (Life Member)

${ }^{3}$ Professor and Head of Department, Dept. of Civil Engineering, University of Canterbury (Fellow).

\section{BEAM-COLUMN JOINTS}

\section{General}

Reinforced concrete beam-column joints have been studied for over 25 years since the first tests were reported in the USA and New Zealand [7]. The shear strength of the joint core, and the anchorage of beam and column reinforcement in the joint core, were both identified as critical features of beam-column joint performance. Pertinent code provisions were first introduced in the 1971 edition of the ACI building code in the United States [1] and in the 1982 concrete design code in New Zealand [8]. However, an internationally accepted unified approach to the design of beam-column joints has yet to emerge.

The aim of the design approach followed in New Zealand $[8,9]$ is mainly to ensure that the strength of a beam-column joint should not be less than that corresponding with the development of the selected plastic hinge mechanism in the frame and that the capacity of a column should not be jeopardised by possible strength degradation of the joint.

\section{Review of Modelling and Design Assumptions}

Figure 1 shows the modelling of the behaviour of an interior beam-column joint when plastic hinges have developed in the beams at the column faces and the columns remain in the elastic range. The actions on the core are represented by internal stress resultants as shown in Fig.1(b). This enables the design horizontal $\left(\mathrm{V}_{\mathrm{jb}}\right)$ and vertical $\left(\mathrm{V}_{\mathrm{jv}}\right)$ joint shear forces to be readily determined. 


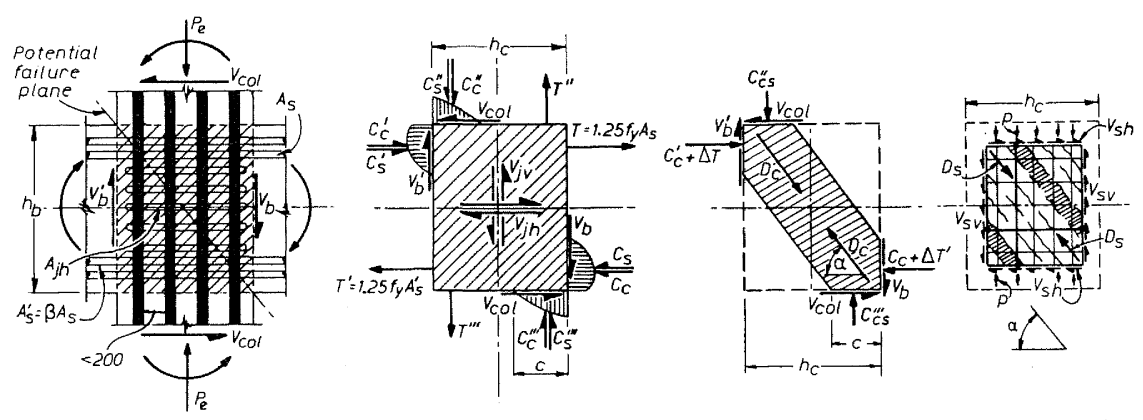

$\begin{array}{llll}\text { (a) Interior Beam-Column Joint (b) Stress Resultants Acting on Joint Core } & \text { (c) Strut Mechanism } & \text { (d) Iruss Mechanism }\end{array}$

FIGURE 1 - External Actions and Internal Stress Resultants at an Interior Beam-Column Joint

According to NZS 3101 [8] the shear strength of a joint core is assumed to be derived from the superposition of the two mechanisms shown in Fig.1. The strut mechanism (Fig.1(c)) is considered to maintain equilibrium of all the concrete compression forces acting on the joint core. This diagonal compression strut can be developed without the contribution of any reinforcement. The truss mechanism (Fig.1(d)) is considered to transfer primarily the bond forces from the reinforcement anchored in the joint to the joint core. It is associated with a diagonal compression field necessitating for equilibrium also the introduction of normal forces at the boundaries of the joint core by means of both horizontal and vertical joint (shear) reinforcement. The superposition of the two mechanisms to resist the total horizontal and vertical joint shear forces is then quantified by

$$
\begin{aligned}
& \mathrm{V}_{\mathrm{jh}}=\mathrm{V}_{\mathrm{ch}}+\mathrm{V}_{\mathrm{sh}} \\
& \mathrm{V}_{\mathrm{jv}}=\mathrm{V}_{\mathrm{cv}}+\mathrm{V}_{\mathrm{sv}}
\end{aligned}
$$

where the shear forces subscripted with $c$ and $s$ are the corresponding contributions of the strut and truss mechanisms, respectively.

When plastic hinges develop in the beams adjacent to the columns, full depth flexural cracks may occur in the beams at the column faces and some yield penetration along longitudinal reinforcement into the joint core may occur. It is expected [8] that in this situation the concrete compression forces in doubly reinforced beams, shown by the stress blocks $\mathrm{C}_{\mathrm{c}}$ and $\mathrm{C}_{\mathrm{c}}^{\prime}$ in Fig. 1(b), would gradually diminish or even vanish and that the internal compression forces would be replaced by a corresponding increase of compression stresses in the beam reinforcement. This inelastic redistribution of internal forces is assumed to result in a drastic reduction or even complete loss of the contribution of the strut mechanism (Fig.1(c)) to joint shear resistance, and corresponding increase of bond forces along beam bars. The code [8] therefore requires that unless significant compression load is acting on the column, the entire horizontal joint shear force $\mathrm{V}_{\mathrm{jh}}$ should be resisted by the joint core shear reinforcement. Also beam bars passing through a joint need to be designed for overstrength stresses developing simultaneously in tension and compression at opposite column faces. This design approach for beam-column joints has led to the need for large amounts of horizontal joint shear reinforcement and to severe restrictions on usable beam bar diameters to prevent excessive bar slip.
Beam-column joints will remain in the elastic range when the plastic hinges in beams are relocated at some distance away from column faces, Consequently the strut mechanism (Fig.1(c)) may be sustained even after significant beam moment reversals. Furthermore the contribution of the strut mechanism may be significant in resisting vertical joint shear when columns are expected to remain elastic irrespective of the location of beam plastic hinges. These considerations allow significant shear strength provided by the strut mechanism, quantified in Eq.(1) by $V_{c h}$ and $V_{c v}$, to be assumed in the code [8] for this case with consequent reduction in the need for joint core shear reinforcement.

Based largely on experimental results obtained between 1975 and 1979 in New Zealand, the current code [8,9] recommends that in terms of the depth of the column $h_{t}$, the diameter of a beam bar $d_{b}$ be restricted to

$$
\mathrm{d}_{\mathrm{b}} \leq 12 \mathrm{~h}_{\mathrm{c}} / \mathrm{f}_{\mathrm{y}}
$$

when plastic hinges could form at column faces, and

$$
d_{b} \leq 15 h_{c} / f_{y}
$$

when the joint could be expected to remain in the elastic range. Thus Eq. (2a) requires that the ratio $h_{c} / d_{b}$ should not be less than 25 and 36 when Grade 300 and Grade 430 steel reinforcement, respectively, are used. It is often found difficult to satisfy these bond criteria.

Similar but less onerous requirements are specified for exterior joints.

\section{Recent Research Results}

A United States/New Zealand/Japan/China collaborative research project has been completed recently $[2,3,5]$. This project was initiated mainly because of the different seismic design approaches adopted in New Zealand [8] and the United States [1] for beam-column joints. Close cooperation in the selection of test specimens and loading sequences enabled a more effective comparison of results to be made. Only the part of the programme undertaken in New Zealand [3] is reported here. Experimental findings from the New Zealand tests have been combined with theoretical considerations to improve existing behavioural modelling, both of which are used to form the basis of some recommended changes to the existing NZS 3101 provisions [8]. 
The great majority of beam-column joint specimens tested since 1967 consisted of plane frame subassemblages. In the international collaborative research programme $[3,5]$, more realistic units were tested by incorporating cast-in-place floor slabs. Full-scale isolated interior joint subassemblages of oneway and two-way frames, and an exterior joint subassemblage of a two-way frame, were constructed to typical New Zealand practice. Seismic actions resulting in progressively increasing displacements were generated by applying quasi-static forces to the free ends of the cantilever beams. Hence uni- or bidirectional earthquake attacks on prototype building frames were simulated. Fig. 2 shows the two-way interior beam-column joint test unit at an advanced stage of testing. To avoid further complexity in the construction of the loading rig, no axial forces were applied to the columns. Thus the effects of vertical axial compression stresses on joints, considered to be beneficial, were not explored in this project.

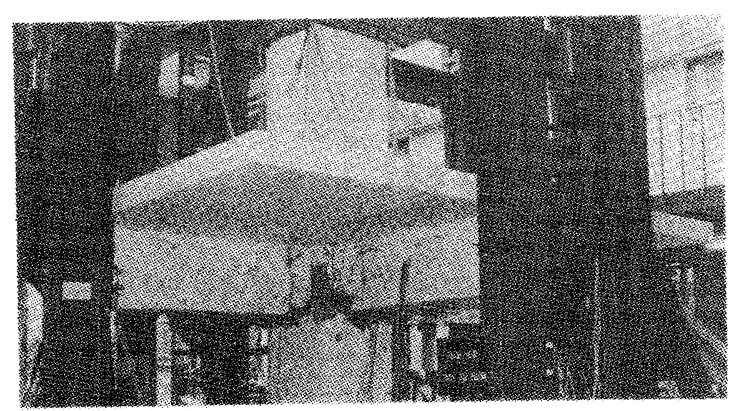

FIGURE 2 - A Two-way Interior Bean-Column-Slab Subassemblage (Unit 2D-I) Tested Under Quasi-Static Cyclic Loading Simulating Severe Earthquake Forces [3]
In the tests [3] all units designed according to NZS 3101:1982 [8] performed very satisfactorily during simulated severe earthquake actions in terms of strength and ductility capacity. Displacement ductility factors of at least 8 and interstorey drift of at least $3.5 \%$ of storey height, well in excess of usable limits in ductile frames, were attained while strength degradation was negligible. The most severe deterioration of response was encountered when testing the interior joint subassemblage of the two-way frame (Unit 2D-I). Fig. 3 shows the lateral forcedisplacement response of this unit in the east-west direction. The reduction in resistance at a peak displacement, for example in cycle $22 \mathrm{~B}$ to a displacement ductility of 4 , resulted from the introduction of a lateral force and corresponding displacement in the north-south direction to the same ductility. At this stage, plastic hinges formed in the beams at all four faces of the column.

The measured column shear force in the east-west direction in Fig. 3 is normalised in terms of the ideal strength based on the ideal flexural strength of the beams calculated using the measured material properties and beam tension reinforcement within the code [8] specified effective width $(1.64 \mathrm{~m})$ of the tension flange. As Fig. 3 shows, participation of reinforcement in tension over the full width $(3.67 \mathrm{~m})$ of the slab would have increased the strength by $14 \%$ to $V_{i}^{*}$. Beam negative moment flexural strength enhancement due to flange action of the slab was found to be greater during uni-directional loading than during bi-directional loading of the test assemblage.

Joint shear failure was not observed in any of the three units. This was also confirmed by measured strains in the horizontal joint core shear reinforcement which showed that unrestricted yielding across a potential diagonal failure plane did not occur. The majority of joint hoops remained in the elastic range. Tests of the other two units were terminated at an interstorey drift of $4.5 \%$ when the bottom bars in the plastic hinges of the beams buckled. Eventual failure of Unit 2D-I, shown in Figs. 2 and 3 , however was due to excessive deterioration of the bottom beam bar anchorages within the joint. This contrasted with the absence of bond loss of identical bars embedded in the joint of the one-way frame.

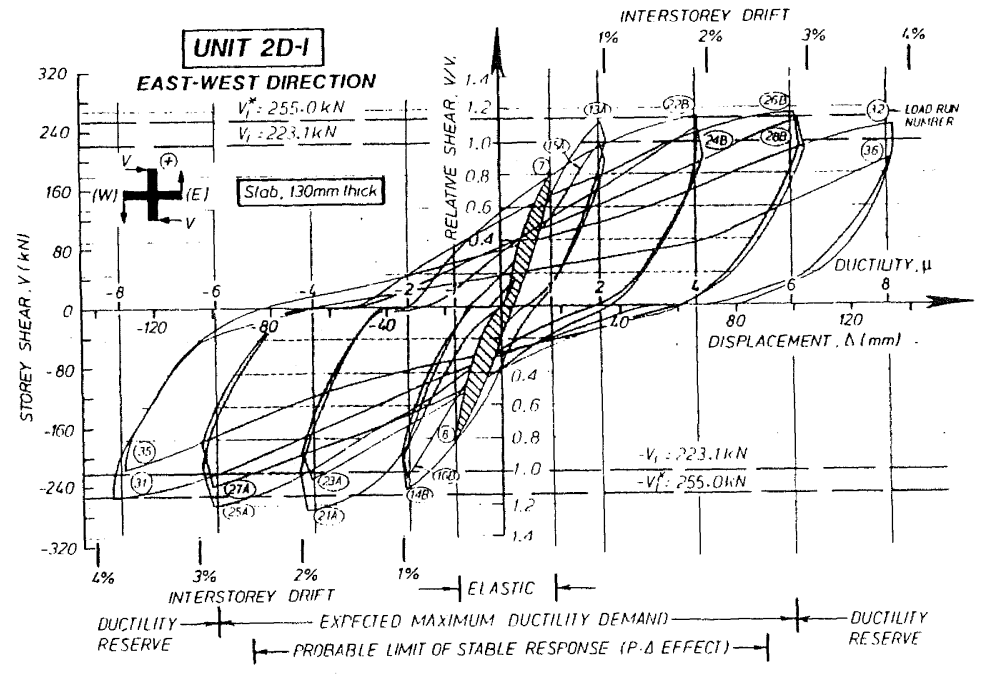

FIGURE 3 - Horizontal Force (Storey Shear) Versus Horizontal Displacement Response of a Two-Way Interior Beam-Column-Slab Joint Subassemblage (Unit 2D-I) [3] 
Park and Dai [6] have also conducted tests recently on one-way beam-column joints subjected to severe simulated seismic loading. Those tests have indicated that some relaxation in the current NZS 3101 [8] requirements for shear reinforcement and beam bar anchorage in interior beam-column joints would still lead to acceptable performance.

\section{Design Recommendations}

Anchorage of bars within interior joints

The existing NZS 3101 requirements (Eq.(2)) were based on experimental studies prior to 1980 in which concrete with specified compression strength $f_{c}^{\prime}$ as low as $20 \mathrm{MPa}$ was specified. The more recent studies $[3,6]$ indicate that a number of factors, additional to those considered in the current code $[8,9]$, should also be taken into account. These factors are:

(a) Some bond deterioration, as a result of yield penetration into the joint core, should be acceptable as long as no excessive slip of longitudinal bars results in the joint core.

(b) As a consequence the compression yield strength of beam bars at overstrength does not necessarily develop at the column faces. Also, account should be taken of situations where it can be demonstrated that yielding of beam bars in compression can never develop. A common example is when the area of beam tension reinforcement at the critical section is less than that of the beam compression reinforcement.

(c) Some allowance for improved bond strength may be justified when $f_{c}$ is high and when the surrounding concrete over a significant portion of the embedment length of a beam bar is subjected to transverse compression from column loading.

(d) Inferior bond performance may be expected in joints of two-way frames, since when plastic hinges develop in all framing beams the concrete surrounding the longitudinal beam bars must be subjected to significant transverse tensile strains.

Design recommendations for the anchorage of beam bars in interior beam-column joints may be derived as follows. Consider a longitudinal bar of diameter $d_{b}$ passing through a column of depth $h_{c}$ as shown in Fig.4. The bar is considered to be yielding in tension at stress $1.25 \mathrm{f}_{\mathrm{y}}$ at one column face and has compressive stress $\gamma \mathrm{f}_{\mathrm{y}}$ at the opposite face, where $\gamma \leq 1$. The average ultimate bond stress is assumed to be $\mathrm{K} V \mathrm{f}_{\mathrm{c}} \mathrm{MPa}$. For equilibrium (see Fig.4)

$$
\frac{\pi}{4} d_{b}^{2}\left(1.25 f_{y}+\gamma f_{y}\right)=\pi d_{b} h_{c} K_{\sqrt[f]{c}}^{\prime}
$$

Now when $f_{c}$ is as low as $20 \mathrm{MPa}$ and $\gamma=1$, NZS 3101 permits $d_{b} / h_{c}=12 / f_{y}$ which when used to calibrate Eq.3 gives $\mathrm{K}=1.51$.

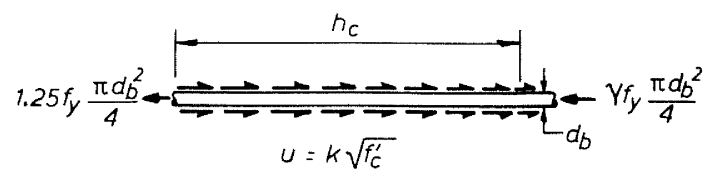

FIGURE 4 - Longitudinal Beam Bar Passing Through a Column at an Interior Beam-Column Joint When Plastic Hinging Occurs in the Beams at the Column Faces
Equation (3) can be written for design use to take into account other factors as follows

$$
\frac{d_{b}}{h_{c}} \leq 1.9 \alpha_{1} \alpha_{2} \alpha_{3} \alpha_{4} \frac{\sqrt{f_{c}^{\prime}}}{f_{y}}
$$

where

$\alpha_{1} \quad$ is a factor which accounts for the level of compressive stress in the beam bar. For bars in the top of beams, the stress in the compression steel will generally not exceed $0.7 \mathrm{f}_{\mathrm{y}}$ and $\alpha_{1}=1.3$ is recommended. For bars in the bottom of beams, it is recommended that $\alpha_{1}=0.3+\beta$ $\geq 1.1$, where $\beta=$ ratio of area of longitudinal bottom steel to area of longitudinal top steel but not to be taken as greater than 1.0 .

$\alpha_{2} \quad$ is a factor to account for the effect of axial compression from the column load on the bond strength. It is estimated that $\alpha_{2}=1.0$ if $\mathrm{P}_{\mathrm{e}} / \mathrm{f}_{\mathrm{c}} \mathrm{A}_{\mathrm{g}} \leq 0.2$ and $\alpha_{2}=0.85$ $\left\{1+\left(\mathrm{P}_{\mathrm{e}} / \mathrm{f}_{\mathrm{c}} \mathrm{A}_{\mathrm{g}}\right)\right\} \leq 1.25$ if $\mathrm{P}_{\mathrm{e}} / \mathrm{f}_{\mathrm{c}}^{\mathrm{g}} \mathrm{A}_{\mathrm{g}}>0.2$, where $\mathrm{P}_{\mathrm{c}}$ is the axial compressive load on the column and $\mathrm{A}_{\mathrm{g}}$ is the gross area of the column.

$\alpha_{3} \quad$ is a factor to account for the detrimental effects resulting from the formation of simultaneous plastic hinges in the beams at all four faces of a column of a two-way frame, taken as 1.0 for two-way frames and 1.2 for one-way frames.

$\alpha_{4} \quad$ is a factor to account for the reduced bond strength of top reinforcement where more than $300 \mathrm{~mm}$ of fresh concrete is cast beneath the bar, compared with bottom reinforcement, taken as 1.0 for top bars and 1.1 for bottom bars.

To illustrate the limitations imposed by Eq.(4) consider longitudinal beam bars passing through an interior joint of a frame with the column subjected to minimum $\mathrm{P}_{\mathrm{c}} / \mathrm{f}_{\mathrm{c}} \mathrm{A}_{\mathrm{g}}$ of 0.2 , where $f_{y}=300 \mathrm{MPa}, f_{c}^{\prime}=30 \mathrm{MPa}$ and $\beta=1.0$ or 0.5 . For this case Eq.(4) gives the limiting values of $d_{b} / h_{c}$ as:

\begin{tabular}{||c|c|c|c||}
\hline Frame Type & Bar Position & $\boldsymbol{\beta}=\mathbf{1 . 0}$ & $\boldsymbol{\beta}=\mathbf{0 . 5}$ \\
\hline \multirow{2}{*}{ One-Way } & Top & $1 / 18.5$ & $1 / 18.5$ \\
& Bottom & $1 / 16.8$ & $1 / 19.9$ \\
\hline \multirow{2}{*}{ Two-Way } & Top & $1 / 22.2$ & $1 / 22.2$ \\
& Bottom & $1 / 20.2$ & $1 / 23.8$ \\
\hline
\end{tabular}

Two beam-column joint specimens tested by Park and Dai [6] were one-way frames with $\mathrm{f}_{\mathrm{c}}$ of about $40 \mathrm{MPa}, \beta=0.51$, Grade 300 beam steel cast as bottom bars with the specimen lying on its side (that is, $\alpha_{4}=1.1$ ), and columns with zero axial load. For these two units Eq.(4) requires $d_{b} / h_{c} \leq 1 / 14.6$ for top bars. Both units had $d_{b} / h_{c}=1 / 14.5$ and their performance under simulated severe loading was satisfactory.

\section{Joint shear strength}

Studies have indicated that the relative contributions of the shear resisting mechanisms in joints, highlighted in Fig. 1, are strongly influenced by the distribution of bond forces along bars anchored within such joints. After the formation of diagonal cracks efficient bond transfer will require a major fraction of the joint shear force to be transmitted by the truss mechanism (Fig.1(d)). On the other hand, some deterioration of bond and a consequent reduction in the ability of beam bars to resist compression forces, will result in an increased contribution to the shear resistance of the strut mechanism (Fig.1(c)). 
Modelling details of a refined strut mechanism are presented in Fig.5. After a number of inelastic stress reversals, the total force developed in the top beam bars, $\mathrm{T}+\mathrm{C}_{s}^{\prime}$, is assumed to be associated with steel stresses shown in Fig.5(b). This force is transferred by means of bond forces to the surrounding concrete of the joint core. Fig.5(c) shows the simplified bond force distribution corresponding to the steel stress variation in Fig.5(b). It is seen that as a result of tensile yield penetration along beam bars into the joint, bond forces over part of the assumed effective embedment length $0.8 \mathrm{~h}_{\mathrm{c}}$ may be much larger than the average value implied for example by Eq.(3). The models in Fig. 5 postulate that the strut mechanism may resist the concrete compression force $\mathrm{C}_{\mathrm{c}}^{\prime}$, part of the total bond force introduced over a fraction of the flexural compression zone of the column, and the column shear force $\mathrm{V}_{\text {col }}$. The remainder of the total bond force may be assigned to the truss mechanism as shown in Fig.1(c). Only this latter mechanism requires joint shear reinforcement. By taking into account the beneficial effect of axial compression it may be shown [3] that the horizontal joint shear force resisted by the strut mechanism is of the order of

$$
V_{c h}=0.3\left(1+3.5 \frac{P_{c}}{f_{c}^{\prime} A_{g}}\right) V_{j h}
$$

When compared with the existing code requirement, Eq.(5) will permit a reduction of as large as $30 \%$ in horizontal joint core reinforcement when the load on the column is negligible.

Two beam-column joint specimens tested by Park and Dai [6] contained horizontal joint core shear reinforcement which had been designed assuming $\mathrm{V}_{\mathrm{ch}}=0.42 \mathrm{~V}_{\mathrm{jh}}$. The performance of both units under simulated severe seismic loading was satisfactory.

Also, it may be shown [3] that with the inclusion of the vertical compression forces p of Fig. 1(d) the vertical joint shear force resisted by the strut mechanism is

$$
\mathrm{V}_{\mathrm{cv}}=0.5 \mathrm{~V}_{\mathrm{jv}}+\mathrm{P}_{\mathrm{e}}
$$

Because of the diminished compressive strength of the concrete in the joint core, resulting from tensile strains in the horizontal and vertical directions, it is considered that the nominal joint shear stresses should be restricted to $0.25 \mathrm{f}_{\mathrm{c}} \leq 9 \mathrm{MPa}$ and $0.20 \mathrm{f}_{\mathrm{c}}$ $\leq 7 \mathrm{MPa}$ in joints of one-way and two-way frames, respectively.

\section{Slab contributions}

Recent tests [3] have verified that reinforced concrete floor slabs, cast monolithically with the beams, enhance the negative moment flexural strength of beams. Existing recommendations in NZS 3101 [8], apparently the first among other codes to introduce this effect, appear to underestimate this increase in flexural strength. Tension flange contributions are also affected by the order of ductility demand imposed on the frame by earthquakes. As Fig. 3 shows, maximum strength for that test unit was developed with displacement ductilities of 4 to 6 . Although it appears that the ideal computed strength of the subassemblage based on the participation of the reinforcement over the full slab width was attained or slightly exceeded, it should be noted that no allowance for strain hardening of the flexural tension reinforcement in the beam web and slab near the column was made in computing $\mathrm{V}_{\mathrm{i}}^{*}$. The presence of transverse beams did not appear to have had a noticeable influence on tension flange contributions. The relative strength enhancement in the one-way frame subassemblage was even greater than that seen in Fig.3.

Based on observations and detailed studies of the mechanisms of flange participation under seismic type of beam actions, it is recommended that both the ideal and the overstrength of beam sections be based on the contribution of all effectively anchored bars in the top of a beam placed within an effective width of $b_{e}$, which may be assumed to be the lesser of:

one quarter of the beam span at each side from the beam centre line;

(ii) one half or one quarter of the distance to an adjacent parallel beam, at each side of the beam centre line, at interior or exterior columns respectively.

Beam overstrength so derived should then be used when designing columns and beam-column joints in accordance with capacity design principles [8]. Slab bars to be considered effective within the width $b_{e}$ are those extending beyond an imaginary line at $45^{\circ}$ degree from the centre of a column. Short top bars in a slab situated at a considerable distance from a column will not satisfy this criterion and hence should be ignored.
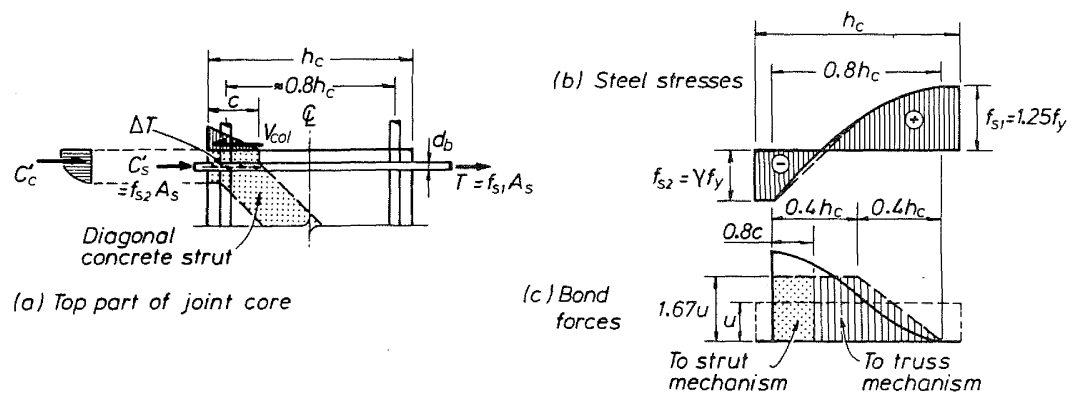

FIGURE 5 - A Refined Strut Mechanism of Transferring Horizontal Shear in an Interior Beam-Column Joint [3] 


\section{COLUMNS}

\section{Transverse Reinforcement for Confinement}

During the last 20 years extensive experimental testing and analysis of reinforced concrete columns subjected to simulated seismic loading has been conducted in New Zealand. The results of some of this research is reflected in the current provisions of NZS 3101[8] for transverse reinforcement for confinement.

Since the publication of NZS 3101, design charts have been derived by Zahn et al [11] to relate the available curvature ductility factor of reinforced concrete column sections to the magnitude of the confining stress applied by transverse spiral and hoop steel and to determine the flexural strength of those confined sections. The design charts were derived from theoretical studies of the cyclic moment-curvature behaviour of reinforced concrete column sections, using analysis that includes the cyclic stress-strain relationships for confined and unconfined concrete and the longitudinal reinforcing steel and takes into account the accumulation of strain energy in the transverse confining steel. The cyclic stress-strain relationships used for confined concrete, due to Mander et al [4], include the effects of various quantities and arrangements of the transverse confining reinforcement. In the analysis the ultimate curvature $\phi_{\mathrm{u}}$ is obtained by imposing four identical cycles of bending moment to peak curvatures of equal magnitude in each direction. The available ultimate curvature is considered to have been reached when one of the following limit conditions is reached: (a) the peak moment resisted in the last cycle has reduced to $80 \%$ of the ideal flexural strength, (b) the strain energy accumulated in the confining reinforcement at the end of four cycles has become equal to its strain energy capacity and the transverse steel fractures, (c) the tensile strain in the longitudinal reinforcing steel has reached that at the ultimate tensile strength, or (d) the compression strain in the longitudinal reinforcing steel has reached that when significant inelastic buckling occurs. The first of these four limit conditions to be reached defines the available ultimate curvature $\phi_{\mathrm{u}}$. Generally either limit condition (a) or (b) was found to govern. A range of design charts for the available curvature ductility factor $\phi_{\mathrm{u}} / \phi_{\mathrm{y}}$ of circular and rectangular reinforced concrete columns were derived [11] where $\phi_{\mathrm{y}}$ is the curvature at first yield. The design charts plot the axial load ratio $\mathrm{P}_{\mathrm{c}} / \mathrm{f}_{\mathrm{c}} \mathrm{A}_{\mathrm{g}}$ against curvature ductility factor $\phi_{\mathrm{u}} / \phi_{\mathrm{y}}$ for various ratios of effective lateral confining stress to concrete compressive strength $\mathrm{f}_{\mathrm{r}} / \mathrm{f}_{\mathrm{c}}$ and for various $\rho_{\mathrm{l}} \mathrm{m}$ values, where $\rho_{\mathrm{t}}$ is the longitudinal steel ratio and $\mathrm{m}=\mathrm{f}_{\mathrm{y}} / 0.85 \mathrm{f}_{\mathrm{c}}$. The effective lateral confining stress is dependent on the spacing, area and yield strength of the transverse bars. Design charts were also derived to determine the flexural strength of column sections including the influence of the increase in the concrete compressive strength and ductility capacity due to confinement.

Watson and Park [10] have used the design charts for ductility derived by Zahn et al [11] to obtain refined design equations for the quantities of transverse confining reinforcement required in the potential plastic hinge regions of reinforced concrete columns. Typical ranges of the axial load ratio $\mathrm{P}_{\mathrm{c}} / \mathrm{f}_{c} \mathrm{~A}_{\mathrm{g}}$, the concrete compressive strength $f_{c}^{\prime}$, the mechanical reinforcing ratio $\rho_{\mathrm{t}} \mathrm{m}$, and the cover ratios $\mathrm{c} / \mathrm{h}$ for square and rectangular columns or $\mathrm{c} / \mathrm{D}$ for circular columns, were considered. The 95\% upper-tail values of the area of transverse steel obtained from the design charts and a regression analysis were used to obtain the best-fit equations by the least squares method. The derived equation for rectangular sections is as follows:

$$
\frac{A_{s h}}{s_{h} b_{c}}=\left\{\frac{A_{g}}{A_{c}} \frac{\left\{\left(\phi_{u} / \phi_{y}\right)-33 \rho_{t} m+22\right\}}{111} \frac{f_{c}^{\prime}}{f_{y h}} \frac{P_{c}}{\phi f_{c}^{\prime} A_{g}}\right\} \begin{aligned}
& -0.006 \\
& (7)
\end{aligned}
$$

For circular sections, $\rho_{\mathrm{s}}$ is 1.4 times the right hand side of Eq.(7). In Eq.(7), $A_{\mathrm{sh}}=$ area of transverse bars in direction under consideration within centre to centre spacing of hoop sets $s_{b}, b_{c}=$ dimension of core of column at right angles to direction of transverse bars under consideration measured to the centre line of the perimeter hoop, $A_{g}=$ gross area of column, $A_{c}=$ core area of column, $\phi_{\mathrm{u}} / \phi_{\mathrm{y}}=$ curvature ductility factor, $\rho_{\mathrm{t}}=$ $\mathrm{A}_{\mathrm{st}} / \mathrm{A}_{\mathrm{g}}, \mathrm{A}_{\mathrm{st}}=$ total area of longitudinal column reinforcement, $\mathrm{m}$ $=\mathrm{f}_{\mathrm{y}} / 0.85 \mathrm{f}_{\mathrm{c}}, \mathrm{f}_{\mathrm{y}}=$ yield strength of longitudinal steel, $\mathrm{f}_{\mathrm{yb}}=$ yield strength of transverse steel, $f_{c}=$ concrete compressive cylinder strength, $\mathrm{P}_{\mathrm{c}}=$ axial compressive load on column, $\phi=$ strength reduction factor and $\rho_{\mathrm{s}}=$ ratio of volume of transverse circular hoop or spiral steel to volume of concrete core of column.

The refined equation has had experimental verification [10]. A value of $\phi_{\mathrm{u}} / \phi_{\mathrm{y}}=20$ could be used in Eq. (7) when plastic hinging is expected in a severe earthquake; for example, at the bottom of building frames and in those frames where strong beam-weak column design is permitted. A value of $\phi_{\mathrm{u}} / \phi_{\mathrm{y}}=10$ could be assumed in Eq.(7) when a capacity design procedure is used to reduce the likelihood of plastic hinges forming in columns. The refined design equations give only the transverse reinforcement required for concrete confinement. The transverse reinforcement provided must also be checked to ensure that the tie requirements for preventing premature buckling of longitudinal compression bars, and the requirements for shear reinforcement, are satisfied.

Figure 6 illustrates the difference between the provisions for the transverse reinforcement required for confinement in the potential plastic hinge regions of a $700 \mathrm{~mm}$ square column according to the current New Zealand code [9] for columns when $\phi=1$, the ACI building code [1] (both the ACI 318-83 and the ACI 318-89 requirements are illustrated), and Eq.(7) for required curvature ductility factors $\phi_{u} / \phi_{y}$ of 10 and 20 when $\phi$ $=1$. It is evident that the quantity of transverse reinforcement required for confinement by Eq.(7) reduces significantly with decrease in axial load level and at axial load levels of $\mathrm{P}_{\mathrm{e}} / \mathrm{f}_{\mathrm{c}} \mathrm{A}_{\mathrm{g}}<$ 0.4 are smaller than both the current New Zealand and ACI 318 code requirements. This feature has also been demonstrated by tests in New Zealand $[4,10,11]$.

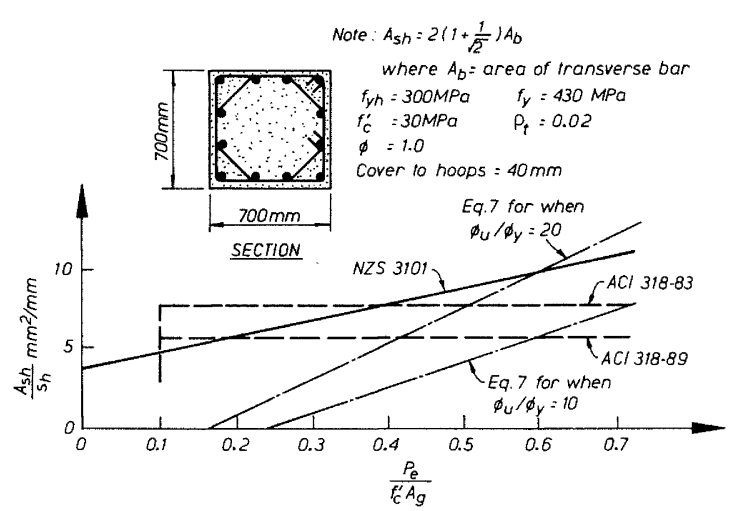

FIGURE 6 Comparisons of ACI and New Zealand Code Recommendations and Eq. (7) for the Quantity of Trans-verse Reinforcement required for Confinement of a Rein forced Concrete Column 


\section{CONCLUSIONS}

Research conducted into the behaviour of ductile moment resisting frames, since the issue of the seismic provisions of the New Zealand concrete design code NZS 3101 in 1982, has shown that:

1. Horizontal reinforcement required for shear resistance in interior beam-column joints can be reduced by at least $30 \%$.

2. Some relaxation of the bond requirements for interior beam-column joints may be permitted, especially when $f_{c}^{\prime}$ is high.

3. Transverse reinforcement required for confinement in the potential plastic hinge regions of columns can be reduced in lightly loaded columns but may need to be increased in heavily loaded columns.

\section{ACKNOWLEDGEMENTS}

The financial support of the Building Research Association and the Ministry of Works and Development is gratefully acknowledged.

\section{REFERENCES}

1. American Concrete Institute. 1989, 1983, 1977, 1971 and earlier years. Building code requirements and commentary for reinforced concrete. ACI 318. Detroit.

2. American Concrete Institute. 1991. "Design of BeamColumn Joints for Seismic Resistance", Special Volume SP-123, Detroit.

3. Cheung, P.C.,Paulay, T. and Park, R. 1991. Seismic design of reinforced concrete beam-column joints with floor slab. Department of Civil Engineering, University of Canterbury, New Zealand. Research Report 91-4.

4. Mander, J.B., Priestley, M.J.N. and Park, R. 1984 Seismic design of bridge piers. Department of Civil Engineering, University of Canterbury, New Zealand. Research Report 84-2.

5. Park, R. 1989. United States/New Zealand/Japan/China collaborative research project on the seismic design of reinforced concrete beam-column-slab joints. Bulletin of the New Zealand National Society for Earthquake Engineering 22(2) : 122-126.

6. Park, R. and Dai, Ruitong. 1988. A comparison of the behaviour of reinforced concrete beam-column joints designed for ductility and limited ductility. Bulletin of the New Zealand National Society for Earthquake Engineering 21(4):255-278.

7. Park, R. and Paulay, T. 1975. Reinforced concrete structures. John Wiley \& Sons, New York.

8. Standards Association of New Zealand. 1982. Code of practice for the design of concrete structures. NZS 3101: Parts 1 and 2. Wellington.

9. Standards Association of New Zealand. 1989. Amendment No.1 to NZS 3101:Parts 1 and 2 . Wellington.

10. Soesianawati Watson and Park, R. 1989. Design of reinforced concrete frames of limited ductility. Department of Civil Engineering, University of Canterbury, New Zealand. Research Report 89-4.

11. Zahn, F.A., Park, R. and Priestley, M.J.N. 1986. Design of reinforced concrete bridge columns for strength and ductility. Department of Civil Engineering, University of Canterbury, New Zealand. Research Report 86-7. 